\title{
A política de integração curricular no âmbito do PROEJA: entre discursos, sujeitos e práticas
}

Monica Ribeiro da Silva*

\section{Resumo}

0 artigo resulta de pesquisa que tem como objetivo analisar uma política curricular que visa a integração entre educação profissional e educação geral. Toma por referência o Programa de Integração da Educação Profissional Técnica de Nível Médio na Modalidade de Educação de Jovens e Adultos (PROEJA), em implantação no estado do Paraná. Analisa o processo de construção de propostas curriculares a partir de dois eixos investigativos: as interpretações feitas pelos sujeitos-autores das propostas acerca do currículo integrado e as interpretações desses mesmos sujeitos acerca da proposição do trabalho como princípio educativo, presentes nos Documentos normativos da política mencionada. As observações e relatos de campo evidenciam, dentre outros aspectos, um conjunto de limitações presentes nesse processo derivados, em parte, de interpretações divergentes do que seja integração curricular e da multiplicidade de significados atribuídos à ideia de trabalho como princípio educativo.

Palavras-chave: Currículo integrado. Educação profissional. Ensino médio integrado. Educação de Jovens e Adultos.

\section{The curricular integration policy in PROEJA: discourse, subject and practice Abstract}

This article is the result of a study that aimed to analyze the implementation of a curricular policy that seeks to integrate professional education with general education. The reference point is the Program for the Integration of Mid-Level Professional Technical Education in the Field of Young People and Adults (PROEJA). The study analyzes the construction process of curricular proposals from two research viewpoints: interpretations made by the subjects/authors of 
the proposals concerning the integrated curriculum and the interpretations of these same subjects concerning the proposition of work as an educational principle, as found in the normative documents of the aforementioned policy. Observations and field reports have shown, among other aspects, a set of limitations to this process, in part deriving from diverging interpretations of what curricular integration is and the number of meanings attributed to the idea of work as an educational principle.

Keywords: Curricular integration. Professional education. High school. Adults education.

\section{La politica de integración curricular en el ámbito del PROEJA: entre discursos, sujetos $y$ prácticas \\ Resumen}

El presente artículo es fruto de una investigación que tiene como objetivo analizar la implantación de una política curricular que busca la integración entre educación profesional y educación general. Toma como referencia el Programa de Integración de la Educación Profesional Técnica de Nivel Medio en la Modalidad de Educación de Jóvenes y Adultos, PROEJA, el cual se está implantando en la provincia de Paraná (sur de Brasil). Se analiza el proceso de construcción de propuestas curriculares a partir de dos ejes de investigación: las interpretaciones realizadas por los sujetos autores de las propuestas acerca del currículo integrado y las interpretaciones de esos mismos sujetos sobre la proposición del trabajo como principio educativo, presentes en los Documentos normativos de la política mencionada. Las observaciones y relatos de campo ponen de manifiesto, entre otros aspectos, un conjunto de limitaciones presentes en dicho proceso, derivadas, en parte, de interpretaciones divergentes sobre lo que es integración curricular y de la multiplicidad de significados atribuidos a la idea de trabajo como principio educativo.

Palabras clave: Currículo Integrado. Educación Profesional. Enseñanza Media Integrada. Educación de Jóvenes y Adultos.

\section{Introdução}

O Programa Nacional de Integração da Educação Profissional com a Educação Básica na Modalidade de Educação de Jovens e Adultos (PROEJA) foi instituído pelo Decreto $n^{\circ} .5 .840$ (BRASIL, 2006) e constitui-se em uma ampliação do Decreto $n^{\circ}$. 5.478 (BRASIL, 2005), que cria o Programa, mas o restringia ao âmbito das instituições federais de educação tecnológica. Essa política amplia a oferta da educação profissional integrada à educação geral, posta inicialmente, pelo Decreto $n^{\circ} .5 .154$ 
(BRASIL, 2004) que, dentre outras disposições, possibilita a oferta da educação profissional de nível ensino médio em três modalidades: subsequente, concomitante e integrada. É a partir desta última que se propõe para a Educação de Jovens e Adultos (EJA), preferencialmente, um projeto político-pedagógico tendo como produto um currículo integrado.

O Documento Base do PROEJA, elaborado pela Secretaria de Educação Profissional e Tecnológica (SETEC), propõe os princípios e concepções que devem fundamentar o Programa e as formas de organização para um currículo integrado. Uma das finalidades anunciadas para o Projeto Político Pedagógico do Programa da Educação Profissional integrada ao Ensino Médio na Modalidade de Jovens e Adultos seria, ainda, a de tentar romper com a dualidade entre ensino científico e ensino técnico. Para tanto, propõe que o Programa se desenvolva a partir de um currículo integrado.

Nessa direção, o Documento Base destaca que o Programa tem como prioridade a formação profissional, o que constitui um elemento inovador, e que seria importante pensá-la à luz de outros aspectos considerando que os jovens e adultos que constituem o público-alvo do PROEJA por muitos motivos só concluíram o ensino fundamental, seja na modalidade EJA, ou não. Além disso, estar-se-ia diante do desafio de tentar não repetir a marca da história no Brasil no que se refere à educação de jovens e adultos, caracterizada por políticas descontínuas e de formação precarizada.

A EJA na perspectiva do ensino médio integrado à educação profissional deve pautar-se, segundo o Documento Base, em fundamentos político-pedagógicos estabelecidos como norteadores de uma organização curricular integrada, "visando à qualificação social e profissional articulada à elevação da escolaridade" (BRASIL, 2007, p. 53).

Como um dos princípios definidos com vistas a consolidar os fundamentos do PROEJA é estabelecido o trabalho como princípio educativo, assim compreendido:

\begin{abstract}
A vinculação da escola média com a perspectiva do trabaIho não se pauta pela relação com a ocupação profissional diretamente, mas pelo entendimento de que homens e mulheres produzem sua condição humana pelo trabalho, ação transformadora no mundo, de si, para si e para outrem (BRASIL, 2007, p. 42).
\end{abstract}

Na esfera do Estado do Paraná, a Secretaria de Estado da Educação (SEED/PR) manifestou a intenção de incorporar o PROEJA em sua oferta de Educação Profissional de nível médio já em 2007. Para esse fim, organizou, ao longo desse ano, encontros e oficinas junto aos diretores e professores das escolas com a participação dos coordenadores da Educação Profissional e da Educação de Jovens e Adultos dos Núcleos Regionais de Educação, com o fim de discutir e viabilizar a implantação do PROEJA. Ao longo do 
ano procedeu-se à definição dos Cursos, critérios para a oferta, número de turmas, localização das escolas, dentre outros aspectos concernentes à implantação. Juntamente com este procedimento, desencadeou-se um processo de elaboração das propostas pedagógicas dos cursos que passariam a ser ofertados em 2008.

Conforme consta do Documento Educação Profissional Integrada à Educação de Jovens e Adultos (PARANÁ, 2007), elaborado com a finalidade de orientar o processo de construção e implantação de cursos que integrem educação geral e formação profissional de nivel médio, seriam ofertados, em 2008, 76 Cursos da modalidade PROEJA, em 72 estabelecimentos de ensino já credenciados para oferta de Educação Profissional. Neste Documento, se afirma que o diagnóstico das demandas resultou de ação da qual participaram as equipes dos 32 Núcleos Regionais de Educação do estado, diretores, professores, alunos e a comunidade em geral. Para 2008, estavam previstos os seguintes cursos: Técnico em Administração, Secretariado, Enfermagem, Agente Comunitário de Saúde, Segurança do Trabalho, Nutrição, Meio Ambiente, Química, Construção Civil, Eletromecânica e Logística. A oferta para 2008 pretende atingir próximo a cinco mil alunos, com matrículas previstas para o primeiro semestre (2485) e segundo semestre (2485).

É neste contexto que se desenvolve a pesquisa da qual resulta o presente texto. A metodologia constou do acompanhamento, na condição de observadores ${ }^{1}$, dos Encontros e Oficinas mencionados. A partir dos relatos de campo, buscou-se analisar o processo de definição das bases curriculares do PROEJA neste estado, tendo como fio condutor da investigação o desafio da integração curricular.

0 texto tem, assim, como objetivo, sistematizar aspectos da implantação do PROEJA, particularmente no que se refere à construção de trajetórias curriculares que integrem cultura geral e formação específica. Está estruturado em dois momentos: o primeiro se refere a uma breve discussão sobre o Documento Orientador produzido pela SEED/PR intitulado Educação Profissional Integrada à Educação de Jovens e Adultos; e o segundo, concernente à análise das Oficinas promovidas pela Secretaria de Estado da Educação que tiveram por finalidade a elaboração das propostas pedagógicas dos cursos que seriam ofertados nos diferentes municípios.

0 procedimento de análise do processo de construção das propostas curriculares se orientou a partir de dois eixos investigativos: a interpretação feita pelos sujeitos-autores das propostas do que é a perspectiva curricular integrada e a interpretação feita por esses mesmos sujeitos acerca da proposição de que o trabalho, tomado como princípio educativo, constituir-se-ia em eixo integrador entre os conteúdos da educação geral e os conteúdos da formação profissional. Com base nesses eixos investigativos analisa-se

\footnotetext{
Do conjunto de pesquisadores faziam parte professores de três instituições universitárias do estado (duas federais e uma estadual) e alunos de mestrado e doutorado destas instituições.
} 
o processo de construção do texto curricular em seus elementos constitutivos: justificativa; perfil do egresso; objetivos e organização curricular propriamente dita.

Parte-se do pressuposto de que o processo de transferência de proposições curriculares de um contexto para outro se expressam por meio de um movimento de recontextualização (BERSTEIN, 1996) a partir do qual se verificam procedimentos de seleção e de deslocamento de significados. Isso traz como consequência, em se tratando de políticas curriculares, um distanciamento entre o discurso oficial e a incorporação das proposições pela escola.

\section{Considerações conceituais: integração curricular e o trabalho como princípio educativo}

A perspectiva de integração curricular no contexto recente da educação profissional brasileira remete à construção de uma proposta capaz de articular a teoria e ação curricular sustentados no e pelo princípio educativo do trabalho:

0 trabalho, nos sentidos ontológico e histórico, é princípio e organiza a base unitária do ensino médio por ser condição para se superar um ensino enciclopédico que não permite aos estudantes estabelecer relações concretas entre a ciência que aprende e a realidade em que vive. É princípio educativo, ainda, porque leva os estudantes a compreenderem que todos nós somos seres de trabalho, de conhecimento e de cultura e que o exercício pleno dessas potencialidades exige superar a exploração de uns pelos outros. (RAMOS, 2008, p. 4).

A especificidade do PROEJA indica uma abordagem curricular capaz de integrar conteúdos da formação geral de nível médio e conteúdos de um campo profissional específico, assegurando, ainda, a particularidade da Educação de Jovens e Adultos. Desse modo, adquire relevância o conceito de integração. Conforme Ciavatta (2005, p. 146):

Remetemos o termo [integrar] ao seu sentido de completude, de compreensão das partes no seu todo ou da unidade no diverso de tratar a educação como uma totalidade social, isto é, nas múltiplas mediações históricas que concretizam os processos educativos [...]. Significa que buscamos enfocar o trabalho como princípio educativo, no sentido de superar a dicotomia trabalho manual/trabalho intelectual, de incorporar a dimensão intelectual ao trabalho produtivo, de formar trabaIhadores capazes de atuar como dirigentes e cidadãos.

A integração entre conhecimentos científicos e tecnológicos implicaria, assim, na superação da mera justaposição de disciplinas, e ainda na tentativa de promover uma articulação entre saber científico e saber técnico com vistas à não reprodução da dua- 
lidade, marca histórica das relações entre formação científica e formação para o trabaIho no âmbito do nivel médio de ensino. Há que se destacar o significado de integração na perspectiva da simultânea referência aos conhecimentos científicos, tanto de cunho geral quanto específicos. Ou seja, a inter-relação entre ciência, trabalho e cultura.

A efetivação de um reordenamento curricular com base nesses postulados, traria, ainda, desdobramentos político-pedagógicos resultantes do processo de repensar as práticas de ensino, de planejamento e de avaliação. Essa necessidade encerraria a construção da perspectiva integrada no escopo dos desafios epistemológicos que oportunizariam rever a relação que alunos e professores têm travado historicamente com o conhecimento no interior das formas escolares consolidadas.

As proposições de integração curricular remetem à ideia de trabalho como princípio educativo, e sinalizam na direção das proposições de Antonio Gramsci $(2000 a, 2000 b)$ que, ao fazer a critica à escola tradicional enfatiza o modo como esta escola está organizada de modo tratar a ciência de maneira abstraída das relações sociais. Assevera o intelectual italiano que o trabalho, ao se converter em princípio educativo, seria capaz de produzir, na escola, uma formação unitária por meio da articulação entre ciência e técnica.

Gramsci (2000a), em Americanismo e fordismo, afirma o quanto a racionalidade do trabalho, na forma capitalista mais desenvolvida, se materializa no sacrificio do trabaIhador. Porém, contraditoriamente, são nas consequências históricas e culturais do trabalho alienado que o autor localiza as possibilidades de superação da alienação, na medida em que todos os homens, indistintamente, permanecem intelectuais, ainda que nem todos desempenhem na sociedade as funções próprias do trabalho intelectual.

0 trabalho industrial moderno é tomado como princípio educativo fundamental, pois para Gramsci (2000a) o trabalho seria, por excelência, elemento integrador entre cultura e ciência e por essa razão, deveria orientar todo o processo educativo no âmbito da escola, chamada, devido a essa possibilidade integradora, de escola unitária ou escola "desinteressada" do trabalho.

A escola "desinteressada" do trabalho teria como intenção e fundamento a compreensão objetiva da ciência e da tecnologia como base dos processos produtivos.

No mundo moderno à educação técnica, estreitamente ligada ao trabalho industrial, mesmo ao mais primitivo e desqualificado, deve constituir a base do novo tipo de intelectual [...]. Da técnica-trabalho, eleva-se à técnica-ciência e à concepção humanista histórica, sem a qual permanece especialista e não se chega dirigente (especialista mais político) (GRAMSCl, 2000b). 
A formação unitária obtida por meio da integração entre ciência e trabalho está na base da proposição gramsciana, cujo método tomaria o principio educativo do trabalho, identificado como espaço do trabalho diretamente produtivo:

0 conceito do equilibrio entre ordem social e ordem natural com base no trabalho, na atividade teórico-prática do homem, cria os primeiros elementos de uma intuição do mundo liberta de toda magia ou bruxaria, e fornece o ponto de partida para o posterior desenvolvimento de uma concepção histórica, dialética, do mundo, para a compreensão do movimento e do devir, para a avaliação da soma de esforços e de sacrificios que o presente custou ao passado e que o futuro custa ao presente, para a concepção da atualidade como síntese do passado, de todas as gerações passadas, que se projeta no futuro (GRAMSCl, 2000b).

0 debate acerca do principio educativo do trabalho tem sido revigorado provavelmente em virtude dessas proposições. É o que mostra, por exemplo, a pesquisa de Sousa Junior (2010), que toma como objeto de discussão a validade do princípio educativo do trabalho tendo por referência as análises de Lessa (2007) e Tumolo (2001). Sobre este último, assevera:

A recusa de Tumolo de que o trabalho possa ser princípio educativo de uma proposta de educação emancipadora parece conter a recusa do princípio educativo do trabalho e isso se deve ao seu entendimento do trabalho no capitalismo como total negatividade. Essa posição, por sua vez, parece ocultar uma concepção da educação como total positividade. Ora, educar/formar não é apenas construir personalidades solidárias, criativas, éticas, etc.. 0 trabalho tem caráter educativo porque ele põe, constrói, afirma ou modifica o ser social independentemente da direção ou perspectiva para a qual aponte esse processo (SOUSA JUNIOR, 2010, p. 15).

Após extensa explanação, o autor conclui que a recusa desses autores ante a ideia de trabalho como princípio educativo se dá porque ambos "ignoram ou desconsideram a distinção entre "trabalho como princípio educativo" e "principio educativo do trabalho" ${ }^{2}$. Dessa análise se pode depreender, dentre outros aspectos, que se está diante de uma formulação complexa, que ao ser tomada como referência para proposições de cunho pedagógico curricular exige intensa análise e reflexão.

2 Essa distinção é explicitada pelo autor de forma bastante pertinente: "Entendemos por princípio educativo do trabalho a qualidade inerente à atividade vital - primeira das formas de objetivação humana, operada pelo ser social em intercâmbio com a natureza para a produção e reprodução da sua existência - de formar/transformar/educar, enfim, tornar o ser social enquanto tal. [...] Já por trabalho como princípio educativo entendemos a utilização da experiência do/no trabalho como fundamento de uma proposta pedagógica" (SOUSA JUNIOR, 2010, p. 1). 


\section{Documento Orientador do PROEJA no Paraná}

O Documento Orientador para a Educação Profissional integrada ao Ensino Médio na modalidade de Educação de Jovens e Adultos no Paraná - PROEJA- foi elaborado pelo Departamento de Educação e Trabalho, e afirma que essa política foi assumida em conjunto por este Departamento e pelo Departamento de Diversidade e de Educação Básica da Secretaria de Estado da Educação, onde estava sediada a EJA.

0 Documento paranaense incorpora algumas das proposições do Documento Base do PROEJA (BRASIL, 2006) produzido pelo Ministério da Educação e contempla orientações para a implantação do Programa no Estado do Paraná. Está estruturado em onze seções ${ }^{3}$, de constitucionalização e justificação para essa política, até direcionamentos de ordem mais especifica, como organização de turmas, avaliação e formação de professores. A presente análise se concentra em uma discussão qualitativa da seção 4 - Princípios norteadores da Educação Profissional integrada à Educação de Jovens e Adultos no Paraná; da seção 5 Perspectivas de Integração da Educação Profissional Técnica de Nível Médio na Modalidade de Educação de Jovens e Adultos no Paraná e da seção 6 - Fundamentos político-pedagógicos do currículo da Educação Profissional integrada à educação de Jovens e Adultos.

0 Documento Orientador contextualiza a Educação Profissional no Paraná e afirma que esse estado, mesmo ainda durante a vigência do Decreto no. 2.208 (BRASIL, 1997), implementou a oferta da Educação Profissional integrada ao Ensino Médio, e, com a promulgação do Decreto no 5.154 (BRASIL, 2004), deu-se a consolidação do que já estava sendo retomado desde 2003. As discussões acerca do Ensino Médio Integrado apontaram para uma perspectiva de formação capaz de articular trabalho, cultura, ciência e tecnologia, instituída como princípios fundantes da organização curricular integrada. Com isso, o Estado do Paraná assume este princípio, tendo por referência as formulações de Antonio Gramsci (2000b).

Desse modo, a SEED, através do Departamento de Educação Profissional, assumiu o compromisso com uma política de Educação Profissional que tem o trabalho como princípio educativo, princípio este que considera o homem em sua totalidade histórica, e a articulação entre trabalho manual e intelectual a partir do processo produtivo com todas as contradições dai decorrentes para os processos de formação humana. (PARANÁ, 2007, p. 8).

\footnotetext{
1. Contextualização da Educação Profissional no Paraná. 2. Contextualização da Educação de Jovens e Adultos no Paraná. 3. Política Pública de Integração da Educação Profissional Técnica de Nível Médio na Modalidade de Educação de Jovens e Adultos. 4. Princípios Norteadores da Educação Profissional integrada à educação de Jovens e Adultos no Paraná. 5. Perspectivas de Integração da Educação Profissional Técnica de Nível Médio na Modalidade de Educação de Jovens e Adultos no Paraná. 6. Fundamentos político pedagógicos do currículo da Educação Profissional integrada à educação de Jovens e Adultos. 7. Projeto Político-pedagógico integrado. 8. Organização de Turmas. 9. Avaliação. 10. Formação Continuada. 11. Perfil do Professor da Educação Profissional integrada à educação de Jovens e Adultos. (PARANÁ, 2007).
} 
Nas seções quatro e cinco do Documento Orientador (PARANÁ, 2007, p. 14, 19), as referências ao trabalho como principio educativo estão assim explicitadas:

0 trabalho como principio educativo, pelo entendimento de que homens e mulheres produzem sua condição humana pelo trabalho - ação transformadora no mundo, de si, para si e para outrem.

[...] Tomar o trabalho como principio educativo, articulando ciência, cultura, tecnologia e sociedade requer, uma sólida formação geral fundamentada nos conhecimentos acumulados pela humanidade e uma organização curricular que promova a apropriação dos saberes científicos e culturais tomando o trabalho como eixo articulador dos conteúdos.

Nas seções quatro, cinco e seis, o Documento (PARANÁ, 2007) traz como fio condutor o desafio da integração curricular - o desafio de integrar educação profissional e educação geral na modalidade EJA, o que, ao mesmo tempo, se apresenta como uma possibilidade de romper com a dualidade histórica entre educação básica e educação profissional, segundo esse Documento. Na seção quatro, um dos tópicos apresenta este desafio da seguinte forma:

e) a integração dos conhecimentos do Ensino Médio na modalidade de Educação de Jovens e Adultos como a formação profissional a partir do trabalho e da prática social, contemplando as diversas áreas que contribuem para a formação integral do cidadão e asseguram a possibilidade de continuidade dos estudos (PARANÁ, 2007, p.15).

Na seção seis, o Documento apresenta a possibilidade desta integração a partir da construção do projeto político-pedagógico do curso.

b) A integração de conhecimentos da formação geral e profissional não se resolve através da junção de conteúdos, ela exige outro tratamento a ser dado ao projeto pedagógico, que tome o processo de trabalho e as relações sociais como eixo definidor dos conteúdos, além dos saberes que compõe as áreas do conhecimento; (PARANÁ, 2007, p.19).

Faz-se a seguir, tomando por referência as proposições acima, uma análise do processo de elaboração das propostas curriculares dos Cursos do PROEJA, com o propósito de dimensionar proximidades e distanciamentos entre essas proposições e o movimento de construção de uma perspectiva curricular integrada. 


\section{As bases curriculares: o processo de construção de uma perspectiva curricular integrada}

\section{Primeiro e o Segundo Encontro: a participação na elaboração do Documento Orientador}

Com o desafio de viabilizar a integração entre educação geral e formação profissional no âmbito do PROEJA foram organizados dois Encontros que tiveram como uma de suas finalidades contribuir com a elaboração do Documento Educação Profissional Integrada à Educação de Jovens e Adultos, aqui chamado de Documento Orientador. Esse documento foi previamente sistematizado por integrantes do DET/SEED e submetido à apreciação dos participantes desses Encontros com o fim de colher críticas e sugestões.

No Primeiro Encontro participaram os coordenadores da Educação Profissional dos Núcleos Regionais de Educação e diretores de algumas escolas. Este se configurou em três ações complementares: uma referente à apresentação de dados primários da Proposta da SEED com vistas à implantação do PROEJA, tais como: 0 que é o programa e para quem se destina; Demarcação de tempos e espaços; Certificação; Legislação; Financiamento; Demandas; Implantação; Seleção e formação dos professores para atuar no âmbito do PROEJA. A segunda ação correspondeu a palestras e mesas redondas, as quais giraram em torno dos temas: Trabalho, Educação Profissional, Currículo Integrado e Especificidades da Educação de Jovens e Adultos. 0 objetivo foi o de contribuir com a formação teórica dos educadores sobre as principais temáticas que integram a Proposta do PROEJA. A terceira ação constituiu-se na organização de grupos com os participantes para a discussão e indicação de sugestões para o formato do processo de implantação do PROEJA, destacando-se aspectos relacionados à formação dos professores, critérios para definir a oferta e o público alvo, estrutura das escolas, integração curricular, dentre outros.

Sobre, especificamente, a questão da integração curricular, os grupos apontaram a necessidade de articulação entre a base comum e a formação profissional, e a necessidade de conhecer conteúdos, metodologia e práticas educativas da EJA e da Educação Profissional. 0 grupo concluiu que a integração pode acontecer por área de conhecimento, através de temas interdisciplinares e transdisciplinares. Percebeu-se que há no discurso dos participantes deste primeiro encontro uma preocupação com a articulação entre teoria prática e uma preocupação expressiva com as condições de estrutura para o programa funcionar.

0 Segundo Encontro centrou-se em três ações articuladas entre si: A primeira referiu-se a palestras as quais trouxeram elementos teóricos sobre os temas afetos à Proposta do PROEJA, tais como: Educação pelo Trabalho x Educação para o Trabalho, Mudanças do Mundo do Trabalho e Educação, Possibilidades Teóricas e Metodológicas 
de Integração Curricular. A segunda ação referiu-se à apresentação de um estudo do Instituto Paranaense de Desenvolvimento Econômico e Social (IPARDES), sobre as potencialidades de geração de emprego nos municípios do Estado do Paraná.

A terceira ação consistiu da organização de grupos com os participantes para a discussão e proposição de sugestões para a construção do Documento Orientador que iria subsidiar as discussões mais descentralizadas e a elaboração da proposta pedagógica dos cursos nesta modalidade de ensino. Naquele momento, o Documento Orientador da SEED se apresentava em uma versão bastante preliminar, e ainda, denominada "Documento de trabalho".

Foi possivel observar que, na maioria dos grupos, a discussão ficou muito centrada nas correções de aspectos formais, nomenclaturas, revisão gramatical, pequenas alterações, etc. Assim, o que era para ser o foco de discussão - análise dos fundamentos políticos, pedagógicos e curriculares, bem como, metodologicamente, promover a articulação entre educação geral e formação profissional no âmbito da proposta curricular integrada - acabou se perdendo na discussão dos grupos. Ao final do texto apontam-se possíveis explicações para isso.

\section{As Oficinas: o professor como sujeito na}

\section{elaboração das Propostas Curriculares Integradas}

No que se refere à elaboração das Propostas Pedagógicas dos Cursos nas doze áreas profissionais que seriam ofertadas, a Secretaria do Estado de Educação organizou 12 oficinas por áreas profissionais, compreendendo vinte e quatro horas de discussão para configuração da Proposta Pedagógica em cada um dessas oficinas. Participaram dois representantes de cada escola, entre eles, professores, diretores e coordenadores dos cursos, além de representantes da SEED e dos Núcleos Regionais de Educação. Tendo em vista a participação nas Oficinas, foi solicitado aos integrantes que realizassem uma leitura prévia dos documentos orientadores, dentre eles: Documento Base do PROEJA, Primeira Versão do Documento Orientador da SEED e a Proposta Pedagógica do Ensino Médio Integrado do respectivo curso. Faz-se necessário destacar que parcela significativa desse grupo não tinha participado dos dois primeiros encontros.

A representante da Secretaria de Estado da Educação, SEED, coordenadora dos grupos, iniciava cada oficina com algumas orientações para os participantes, a saber: que 0 objetivo da oficina era a elaboração da Proposta Curricular; e que a base da elaboração dessas Propostas, para a maioria dos cursos, seriam as Propostas Curriculares dos cursos já existentes e ofertados na modalidade regular do Ensino Médio Integrado. Com exceção dos cursos Técnico em Nutrição, que não possui oferta no âmbito da rede estadual, e dos Cursos Técnico em Enfermagem e Técnico em Segurança do Trabalho, que possuem oferta, porém na modalidade subsequente, os demais tiveram sua propostas elaboradas a partir de outras existentes e ofertadas na modalidade regular. 
A análise desse processo de elaboração das Propostas Curriculares para o PROEJA guiou-se por dois eixos investigativos: o da integração curricular e o do trabaIho como eixo integrador entre formação geral e formação profissional. Buscou-se analisar como os sujeitos - autores das propostas - incorporaram essas proposições presentes no Documento Orientador do PROEJA, que interpretação fizeram delas e como encaminharam sua incorporação no texto das Propostas Curriculares. A análise é feita a partir dos registros em seis das doze Oficinas realizadas.

Com relação ao primeiro eixo, a preocupação com a questão da integração curricular aparece de forma bastante circunstancial durante o processo de elaboração das Justificativas, Objetivos e Perfil do egresso. Somente em um dos Cursos manifestouse a preocupação de que a perspectiva integrada estivesse posta ao longo da Proposta, e não somente no momento da discussão e definição das disciplinas.

No que se refere à discussão e definição da organização curricular - estrutura dos cursos em termos de disciplinas, ementas, programas e organização temporal foi possivel observar uma multiplicidade de compreensão acerca da perspectiva curricular integrada. É possivel afirmar, no entanto, que a ideia predominante gira em torno de que promover a integração entre os conhecimentos próprios da educação geral e os conhecimentos especificos da formação profissional se circunscreve a um processo por meio do qual se "juntam" conteúdos de diferentes disciplinas em uma única disciplina. Conforme um dos participantes:

É necessário fazer uma análise das ementas para retirar as
repetições. Por exemplo, se Geografia já trata de noções de
cartografia e mapeamento, é desnecessário tratar de novo
em "Estudo de impactos e monitoramento ambiental", como
está na proposta do Ensino Médio Integrado (Participante
de uma das Oficinas).

Embora no primeiro dia de cada Oficina, tenham sido apresentadas as proposições do Documento Orientador, as discussões acerca das disciplinas centraram-se mais na questão da junção dos conteúdos, entendendo-se a integração curricular como junção entre conteúdos específicos da formação profissional e conteúdos da base nacional comum. A questão do trabalho como principio educativo e eixo integrador não foi evidenciada ou apareceu de forma bastante pontual, quando se fazia referência ao pressuposto de que os educandos da EJA trazem experiências distintas dos educandos do Ensino Médio Integrado muitas delas balizadas pela inserção no trabalho.

0 processo de junção de disciplinas foi marcado, por vezes, por disputas "territorializadas", em que alguns dos participantes manifestavam a concordância com proposições nessa direção, e outros se colocavam em oposição à determinada proposta de junção. Frequentemente, esses embates ocorreram sem que se consolidassem ar- 
gumentos ou justificativas assentados nas proposições e principios do Documento Orientador, mas na personificação das disciplinas nos professores que as ministram. A título de exemplificação, reproduz-se abaixo o registro de um dos observadores:

Houve uma discussão acirrada que permeou toda a Oficina: A permanência de "Anatomia e Fisiologia" como disciplina ou diluir seus objetivos na disciplina Biologia.

A Coordenadora da Oficina, representante da SEED/PR, defendeu que não pode haver uma sobreposição de disciplinas, e de que Fisiologia e Anatomia são conteúdos da disciplina Biologia e não disciplinas em si.

Nesse momento, houve bastante polêmica, pois a professora da área específica presente posicionou-se pela não extinção da disciplina. Considerou que a Biologia é de fato o conhecimento base, mas que se faz necessário fazer a adequada transposição didática desses conhecimentos uma vez que instrumentalizam o próprio curso. E que nem sempre um professor de Biologia tem essa visão.

A professora da área especifica, mesmo tendo prosseguido o trabalho, continuava a se posicionar contra a extinção das disciplinas de Anatomia e Fisiologia. Que se ela voltasse à escola colocando essa mudança curricular, os professores iriam "virar até os mortos no túmulo por conta de não permitir que isso acontecesse". Mas o grupo resolveu tirar essas duas disciplinas com a ressalva de ser aumentada a carga horária para Biologia. Mesmo assim, a professora continuou resistente e solicitou que a disciplina voltasse com o nome de Anatomia e Fisiologia aplicada à [...]. Considerou que a disciplina "Principais doenças Humanas" também é da área de Biologia, no entanto é especifica do curso. Que seria a mesma situação. Foi novamente questionado até que ponto o professor de Biologia daria conta de alguns itens da listagem de conteúdos especificamente da disciplina Anatomia.

Outra professora considerou necessário manter-se a disciplina de Anatomia e Fisiologia e "maquiá-la" com outro nome, mas mantendo a listagem de conteúdos. E que acima de tudo, haveria a necessidade de ser bem criterioso na escolha do professor considerando os conteúdos que ele deverá desenvolver; que muitos professores recém formados não dariam conta dos conteúdos de Biologia, que são mais específicos da área de Enfermagem. Que a carga horária de Biologia no curso deveria aumentar muito para dar conta de todas as especificidades. Que uma possibilidade seria incluir esses conteúdos, portanto, em outra disciplina (Registro de campo de um dos pesquisadores). 
Outra questão pertinente à integração curricular diz respeito à preocupação com o ordenamento temporal. Nessa direção, as falas dos sujeitos-autores das Propostas indicam uma compreensão da temporalidade curricular circunscrita à sequência cronológica das disciplinas e ao adensamento do tempo, tendo em vista se tratar de cursos da modalidade Educação de Jovens e Adultos. A título de exemplificação, reproduz-se o diálogo entre os participantes de uma das Oficinas:

Um Professor afirma que o curso do ensino médio integrado é para quatro anos, e o PROEJA vai formar em três anos. Outro Professor argumenta que a base comum tem 2.400, e agora vai para 1.200. Um outro Professor considera que o aluno é diferente pela idade e conhecimento que traz. Assim, o tempo é diferente. Um dos participantes afirma: Vamos ter de pensar muito os conteúdos, bem pensado, bem enxugado (Registro de campo de um dos pesquisadores).

De outra Oficina reproduz-se a fala de um dos participantes:

Qual o tempo necessário? Qual o tempo necessário para cada disciplina? Este é o maior quebra-pau! Jesus amado! É quase preciso apartar o povo. Não é fácil! Mas se a gente tiver essa visão integrada de currículo, de projeto político pedagógico, quando chegar aí nós não vamos ter problemas, por que nós vamos pensar neste todo, pensar na questão da integração. Para que que eu vou criar esta disciplina se ela já entrou aqui, se ele pode muito bem entrar aqui. Então, é só aumentar o número de horas aqui e este mesmo professor vai trabalhar e ninguém vai perder aula. Ninguém vai perder! (Participante de uma das Oficinas).

Sobre o segundo eixo investigativo - a interpretação dos sujeitos-autores das Propostas sobre a proposição do trabalho como eixo integrador - foi possivel identificar que essa proposição foi considerada nos momentos de discussão e definição das justificativas, objetivos, e do perfil do egresso. No entanto, o trabalho foi considerado prioritariamente em sua dimensão técnica, circunscrita à discussão principalmente ao desempenho do futuro profissional. Foram raras as vezes em que houve alguma manifestação acerca da dimensão ontológica do trabalho. A discussão distanciou-se, assim, consideravelmente, das formulações do Documento Orientador. As asserções acima evidenciam-se nos argumentos dos participantes.

Em uma das Oficinas, a título de ilustração, no momento da definição do perfil profissional um integrante afirmou que não é de competência do técnico tomar decisão, mas atuar, o que sugere o privilegiamento da dimensão do fazer, em detrimento da necessidade do "saber", associado à esfera da ciência. A partir desta fala 
houve uma discussão se o técnico deve tomar decisão ou não. Um dos integrantes reitera que a tomada de decisões pelo técnico vai contra a Lei que regulamenta 0 exercício profissional. Um outro integrante sugere a retirada de "processo de decisão" do perfil do formando, mas um outro participante questiona: "Como pode haver um profissional que não toma decisão?". Um professor assevera, por fim, que o conselho profissional não permite que o técnico nem o tecnólogo tomem decisões, mas somente o bacharel.

Em outra Oficina, afirmou-se que, no que se refere à formação geral, seria importante garantir conhecimentos técnicos e científicos que assegurassem autonomia intelectual e ética no processo de construção humana, mas que o técnico, no que se refere ao exercício profissional, teria que estar subordinado ao profissional formado em nivel superior.

A proposição do trabalho como princípio educativo foi contemplada, portanto, de forma bastante parcial e restritiva, distanciando-se conceitualmente em relação às proposições do documento da SEED, estando presente nas discussões sobre as justificativas, objetivos e perfil do egresso em todos os Cursos. No entanto, foi possivel constatar que tal proposição simplesmente desaparece no momento da discussão sobre organização curricular.

Em nenhuma das Oficinas o principio educativo do trabalho foi tomado como eixo que poderia ser capaz de conferir outra possibilidade interpretativa em direção à integração curricular e à articulação entre educação geral e formação profissional. Os dados coligidos permitem indicar que no processo de elaboração das propostas curriculares se evidencia uma apropriação formal do discurso sobre o princípio educativo do trabalho; e, ainda, que a formulação disciplinar original presente nas propostas já existentes nos cursos de educação profissional integrada ao ensino médio, ponto de referência da elaboração das propostas dos cursos para o PROEJA, se colocara como obstáculo ao avanço na construção de novas possibilidades de integração.

\section{Considerações finais}

Evidenciou-se, nas discussões entre os educadores participantes do processo estudado, uma grande preocupação com o tempo necessário para materializar uma proposta para esta modalidade de ensino. Essa preocupação exprime um cuidado especial com o processo de implantação de uma nova política. Foi possível constatar, entretanto, que o tempo foi um aspecto a partir do qual muitas lacunas se entremearam ao processo de implantação do PROEJA na rede estadual paranaense. É possivel inferir que o resultado final dos Encontros e Oficinas ficou fragilizado pelo pouco tempo conferido para as discussões e para as decisões, por exemplo, no que se refere às propostas curriculares. 
Outro fator a destacar se deve à constatação de que os participantes nem sempre eram os mesmos nos Encontros e Oficinas, o que gerou um processo de descontinuidade das discussões que pode ter interferido nas decisões quanto à implantação e, principalmente, as que se referem às propostas curriculares. Das Oficinas para elaboração das Propostas não estavam presentes professores das disciplinas do Núcleo Comum de formação geral, o que se apresentou como um aspecto dificultador e, por vezes, impeditivo de uma discussão mais qualificada sobre as possibilidades de integração curricular.

Outra constatação relevante é a de que, nas Oficinas, poucas vezes os participantes recorreram ao Documento Orientador, onde se propunham as bases teórico-metodológicas e epistemológicas com vistas à integração curricular. Suas atenções se concentraram nas bases curriculares propostas para o Ensino Médio Integrado na modalidade regular, ou seja, no modelo "já pronto". Desse modo, emerge um questionamento: em que condições os participantes poderiam decidir sobre a integração curricular sem terem um posicionamento claro acerca das proposições do Documento definidor das bases curriculares integradas voltadas, especificamente, para a Educação de Jovens e Adultos?

Apenas em uma das Oficinas se observou uma maior coerência entre as formulações do Documento Orientador e a elaboração da Proposta Curricular. É possivel aventar a hipótese de que isso se deu, provavelmente, porque todo o grupo esteve presente nos Encontros que precederam as Oficinas; para este Curso especificamente, a oferta existente no âmbito do Ensino Médio na modalidade regular é subsequente e não integrada e, ainda assim, o grupo fez um interessante movimento em direção à integração, evidenciando uma abertura do grupo em relação à perspectiva integrada.

Em contrapartida, prevalecem aspectos que se mostraram dificultadores da construção de uma perspectiva curricular integrada. A construção e o significado de alguns conceitos se evidenciaram divergentes entre os sujeitos o que foi acentuado pelas diferenças nas áreas de formação e atuação dos professores, que, muitas vezes preferiram reafirmar suas posições a partir de sua formação inicial, buscando legitimar sua opinião, ao invés de arriscar construir, coletivamente, um consenso.

Por fim, a análise aponta para outras possibilidades explicativas acerca das dificuldades de integração curricular no âmbito da educação profissional técnica de nivel médio na modalidade educação de jovens e adultos: uma dessas dificuldades residiria na proposição do trabalho como princípio educativo, dada a complexidade dessa formulação, agravada pela ausência de familiaridade dos sujeitos com a proposição; outra explicação remeteria à polissemia que comporta o conceito de trabalho (FRIGOTTO, 2009), evidenciada nas falas dos sujeitos nos distintos significa- 
dos a ele atribuídos; por fim, outro elemento a impor limites aos objetivos de integração curricular a partir do trabalho como eixo integrador e princípio educativo estaria no modo como o trabalho se institui em nossa sociedade.

Ainda que se argumente que o trabalho comporta uma dupla dimensão, a de trabaIho alienado e de trabalho em sua possibilidade ontológica, indaga-se em que medida é possivel tomar o trabalho enquanto princípio educativo quando, nitidamente, prevalece no imaginário dos sujeitos as marcas da dimensão do trabalho experienciada socialmente e que resultam do convivio diuturno com as manifestações da forma capitalista de conceber e organizar o trabalho. Por outro lado, o trabalho na condição de princípio educativo demandaria tomá-lo idealmente em sua condição ontológica, considerando a dupla e contraditória expressão do trabalho em nossa sociedade.

A pesquisa ora relatada evidencia que nas falas dos sujeitos partícipes da construção de uma perspectiva curricular integrada considerando a proposição do trabalho como princípio educativo prevalece a ideia de trabalho em sua manifestação histórica, associado, de forma imediata, aos requisitos de inserção no mercado de trabalho, o que resulta, em última análise, na sobrevalorização da técnica em detrimento da base científica do trabalho. Ciência e técnica (tecnologia), associados, compõem a base da ideia de trabalho como princípio educativo em Gramsci, que identifica a dissociação entre esses elementos na sociedade e na escola, epistemológica e pedagogicamente. Propor, então, que se deposite no professor a expectativa e a responsabilidade em promover a integração daquilo que se encontra cindido para além dos muros da escola não se estaria recaindo em uma espécie de "filosofia do sujeito" (BIANCHETTI; JANTSCH, 1995), a partir da qual se depositaria, uma vez mais, no professor, a crença, a expectativa e a responsabilidade de recompor aquilo que está, na sociedade, estruturalmente cindido, separado? Os limites identificados na presente pesquisa sinalizam nessa direção.

Do exposto, é possivel concluir que para que se prossiga em direção a uma efetiva integração curricular entre educação geral e formação profissional, se faz necessário repensar a organização pedagógica e curricular em bases que superem as velhas formas marcadas pela simples justaposição entre esses dois campos da formação. Nesse sentido, torna-se imperativa uma efetiva articulação entre teoria e prática, entre ciência e técnica, entre trabalho e cultura, de modo a gerar a compreensão do significado histórico e social do trabalho, da ciência, da cultura e da tecnologia.

Dito de outro modo, a integração curricular pressupõe uma perspectiva curricular que trate, pelo principio da indissociabilidade, respeitando, porém, as especificidades, a relação entre conhecimentos gerais e tecnológicos ou específicos. Tal perspectiva, construída sobre o eixo integrador trabalho-ciência-cultura-tecnologia, dada sua complexidade e a forma histórica desses elementos em nossa socieda- 
de, impõe necessariamente o envolvimento direto dos sujeitos da escola por meio do estudo e da reflexão crítica profunda acerca do trabalho, da ciência, da cultura e da tecnologia, permitindo maior aproximação de uma possível integração do mundo da cultura com o mundo do trabalho, de uma articulação mais consistente entre formação geral e profissional.

Importa, por fim, lembrar que, conforme Gramsci (2000b, p. 36), para que a escola unitária se realize em pleno sentido é preciso compreender que:

A escola unitária requer que o Estado possa assumir as despesas que hoje estão a cargo da família no que toca à manutenção dos escolares, isto é, requer que seja completamente transformado o orçamento do ministério da educação nacional, ampliando-o enormemente e tornando-o mais complexo: a inteira função de educação e formação de novas gerações deixa de ser privada e torna-se pública, pois somente assim ela pode abarcar as gerações, sem divisões de grupos ou castas. Mas esta transformação da atividade escolar requer uma enorme ampliação da organização prática da escola, isto é, dos prédios, do material científico, do corpo docente, etc.

\section{Referências}

BERSTEIN, B. Classes, códigos e controle: a estruturação do discurso pedagógico. Tradução de Tomaz Tadeu da Silva e Luis Fernando Gonçalves Pereira. Petrópolis, RJ: Vozes, 1996.

BIANCHETTI, L.; JANTSCH, A. P. Interdisciplinaridade: para além da filosofia do sujeito. Petrópolis, RJ: Vozes, 1995.

BRASIL. Decreto $n^{\circ} .2 .208$, de 17 de abril de 1997. Regulamenta o $§ 2^{\circ}$ do art. 36 e os arts. 39 a 42 da Lei $n^{\circ}$ 9.394, de 20 de dezembro de 1996, que estabelece as diretrizes e bases da educação nacional. Diário Oficial [da] República Federativa do Brasil, Brasília, DF, 18 abr. 1997. Disponivel em: <http:// www.planalto.gov.br/ccivil_03/decreto/D2208.htm>. Acesso em: 6 jun. 2011.

Decreto $n^{\circ}$. 5.154, de 23 de julho de 2004. Regulamenta o $§ 2^{\circ}$ do art. 36 e os arts. 39 a 41 da Lei $n^{\circ}$ 9.394, de 20 de dezembro de 1996, que estabelece as diretrizes e bases da educação nacional, e dá outras providências. Diário Oficial da União, Brasilia, DF, 14 jul. 2006. Disponivel em: <http://www.planalto.gov.br/ ccivil_03/_ato2004-2006/2004/decreto/D5154.htm>. Acesso em: 6 jun. 2011. 
BRASIL. Decreto ñ. 5.478, de 24 de junho de 2005. Institui no âmbito das instituições federais de educação tecnológica, o... Diário Oficial da União, Brasilia, DF, 27 jun. 2005. Revogado pelo Decreto no 5.840 de 2006.

Decreto $\mathrm{n}^{\circ}$ 5.840, de 13 de julho de 2006. Institui o Programa Nacional de Integração da Educação Profissional com a Educação Básica na Modalidade de Educação de Jovens e Adultos - PROEJA, e dá outras providências. Diário Oficial da União, Brasilia, DF, 14 jul. 2006. Disponível em: <http://www.planalto.gov.br/ ccivil_03/_ato2004-006/2006/Decreto/D5840.htm>. Acesso em: 6 jul. 2011.

- Ministério da Educação. Secretaria de Educação Profissional e Tecnológica. PROEJA: documento base. Brasilia, DF, 2007.

CIAVATTA, M. A formação integrada: a escola e o trabalho como lugares de memória e de identidade. In: FRIGOTTO, G.; CIAVATA, M.; RAMOS, M. N. Ensino médio integrado. São Paulo: Cortez, 2005.

FRIGOTTO, G. A polissemia da categoria trabalho e a batalha das ideias nas sociedades de classe. Revista Brasileira de Educação, Rio de Janeiro, v. 14, n. 40, jan./abr. 2009.

GRAMSCl, A. Americanismo e fordismo. In: Cadernos do cárcere. Tradução de Carlos Nelson Coutinho. Rio de Janeiro: Civilização Brasileira, 2000a. Caderno 23.

. Os intelectuais, o princípio educativo, jornalismo. In: Cadernos do cárcere. Tradução de Carlos Nelson Coutinho. Rio de Janeiro: Civilização Brasileira, 2000b. Caderno 12.

LESSA, S. Trabalho e proletariado no capitalismo contemporâneo. São Paulo: Cortez, 2007.

PARANÁ. Secretaria de Estado da Educação. Departamento de Educação e Trabalho. Educação profissional integrada à Educação de Jovens e Adultos. Curitiba, 2007.

RAMOS, M. N. Marcos conceituais do ensino médio integrado: proposta para discussão. Brasilia, DF, 2008. Contribuição de Marise Ramos à reunião com a SEB e SETEC/MEC, realizada em Brasilia, nos dias 27 e 28 de maio de 2008. Mimeografado. 
SOUSA JUNIOR, J. Principio educativo e emancipação social: validade do trabalho e pertinência da práxis. In: REUNIÃO ANUAL DA ANPED, 33., 2010, Caxambu.

Trabalhos apresentados... Caxambu, MG: ANPED, 2010. Disponivel em: <http:// www.anped.org.br/33encontro/app/webroot/files/file/Trabalhos\%20em\%20PDF/ GT09-5974-Int.pdf>. Acesso em: 21 fev. 2011.

TUMOLO, P. S. 0 significado do trabalho no capitalismo e o trabalho como princípio educativo: ensaio de análise crítica. In: REUNIÃO ANUAL DA ANPED, 24., 2001, Caxambu. Trabalhos apresentados... Caxambu, MG: ANPED, 2001. Disponivel em: <http://www.anped.org.br/24/ts.htm>. Acesso em: 21 fev. 2011.

Recebido em: 17/03/2010

Aceito para publicação: 21/02/2010 